\title{
Is It Possible to Estimate Spanish Missing Person's Forced and Fatal Outcomes Cases Using Socio-demographic Data? Gender, Age and Nationality
}

\author{
Néstor García-Barceló ${ }^{1,2}$ (D) $\cdot$ Miguel Ángel Alcázar Córcoles ${ }^{1,2}$. \\ Javier Revuelta Menéndez ${ }^{3}$ · Penny Woolnough ${ }^{4}$ · José Luis González Álvarez ${ }^{5}$
}

Accepted: 7 February 2022

(C) The Author(s) 2022

\begin{abstract}
Although research on missing persons has globally increased during the past few years, most of the studies conducted have focused on the description of socio-demographic and situational factors associated with this phenomenon. The aim of this study is to explore in-depth the relation between missing person's socio-demographic factors and missing person's typology and outcomes. A full 1-year sample of police recorded missing persons ( $n=24,284)$ was extracted from the Spanish 'Missing Persons and Unidentified Human Remains (PDyRH)' system and a multivariate statistical approach was used. The findings of this research show that, although nationality and gender are mainly important from a descriptive level, age is the socio-demographic variable that better classifies the typology and outcome of missing person cases. These findings suggest that age is a modulating variable of this phenomenon. Thus, there is a need for the conduction of research for each specific age group focused on identifying psychosocial, criminological and geographical risk factors which could explain missing person case outcomes from a multifaceted approach. Considering previous research in the field, the findings of this research are mostly consistent with these previous studies and entail different implications, both at prevention level and in the scope of police investigations.
\end{abstract}

Keywords Missing persons - Risk assessment - Fatal outcomes · Forced cases · Sociodemographic factors

Néstor García-Barceló

nestor.garcia@icfs-uam.es; nestor.garciab@estudiante.uam.es

1 Department of Biological and Health Psychology, School of Psychology, Autonomous University of Madrid (UAM), Madrid, Spain

2 Institute for Forensic and Security Sciences (ICFS), Autonomous University of Madrid (UAM), Francisco Tomás y Valiente Street, Madrid, Spain

3 Department of Social Psychology and Methodology, School of Psychology, Autonomous University of Madrid (UAM), Madrid, Spain

4 Division of Psychology, School of Health and Social Sciences, Abertay University, Dundee, Scotland

5 Ministry of Interior, Spanish Secretary of State for Security, Madrid, Spain 


\section{Introduction}

Internationally, recorded missing person statistics consistently highlight the scale of the operational challenge faced by police in this area and the need for research to facilitate prevention and maximise the effectiveness of multi-agency response (Ferguson \& Soave, 2020; Gong et al., 2017; National Crime Agency, 2016; National Crime Information CenterFBI, 2017; Spanish Ministry of Interior, 2020; Stevenson \& Thomas, 2018; Todorović \& Butorac, 2017). Central to this is the need to develop critical understanding of the risk factors that may provide an early indication of cases likely to end in a harmful or fatal outcome (García-Barceló et al., 2019). Our purpose in the present research is to make an important first step in this regard by examining whether key missing person factors can be used to statistically determine outcomes and typologies (García-Barceló et al., 2020a, b, c).

Defining and clarifying the phenomena of missing people is a complicated and multifaceted task, and institutions all over the world use different conceptualisations of the phenomenon (García-Barceló et al., 2019). Recently, the UK College of Policing (2021) defined a missing person as 'anyone whose whereabouts cannot be established'. Indeed, within the UK where the above national definition is applied, a study of four hundred and six participants (police officers and civilian staff) empirically analysed perceptions of the definition of missing people, limitations of the definition and components participants felt needed to be included in the definition. The findings showed that $65 \%$ of participants considered the definition adopted was not suitable, comprised inappropriate elements and did not take account of other relevant elements (Shalev-Greene et al., 2019). In Spain, the Ministry of Interior (2021) indicate that a missing person is 'anyone who is absent from his habitual residence for no apparent reason, or whose new residence is unknown, giving rise to the search process focused on his/her own safety and family or social interest'.

Despite definitional challenges and variations, most countries' definition of a missing person speaks to the challenge of locating a person whose whereabouts are unknown, where the disappearance may be out of character and where they may be the subject of crime or at risk of harm (Taylor et al., 2018). In this regard, the UK College of Policing Missing Persons Authorised Professional Practice (ACPO, 2013) differentiates between 'missing person' and 'absent person'. Missing person is considered as 'any person whose whereabouts cannot be established and where the circumstances are out of the character or the context suggests that the person may be subject to a crime or run the risk of selfharm or provocation to a third party'. Absent individuals are defined as those 'who are not currently where they are supposed to be, but there is no apparent risk of suffering harm or causing it to a third party' (ACPO, 2013). The scale of the problem exacerbates this challenge. For example, 219,425 missing persons were recorded in Spain between 2009 and 2020 (Spanish Ministry of Interior, 2021), UK police receive over 300,000 reports per year (National Crime Agency, 2017), over 38,000 missing person reports are made to police every year in Australia (National Missing Persons Coordination Centre, 2019), and in 2019, over 70,000 missing people were recorded in the Canadian Police Information Centre (The National Centre for Missing Persons and Unidentified Remains -NCMPUR, 2019).

With this in mind, there has been a gradual increase in missing persons research over the past 20 years (Taylor et al., 2018). The research has mainly focused on five different facets: explanation of the phenomenon (causes and motives); description of missing people and disappearances; study of the effectiveness of missing person appeals; building empirical 
missing person's typologies; and identification of risk factors of harm/fatal outcomes (e.g. Baker et al., 2002; Biehal et al., 2003; Lampinen et al., 2009; Bonny et al., 2016; Buckley, 2012; Sarkin, 2019; Woolnough et al., 2019; García-Barceló et al., 2020a, b, c; Huey \& Ferguson, 2020; Woolnough \& Cunningham, 2020).

Collectively, however, these studies have been largely descriptive and generally lack explanatory depth (Taylor et al., 2018). Indeed, overall, there are lacks of consolidated theories to explain the missing people phenomenon. Tarling and Burrows (2004) proposed an explanation focused on the existence of social and environmental causal mechanisms: push and pull factors. More recently, Huey and Ferguson (2020) point out that going missing is considered an inadequate coping response when dealing with stressful situations that generate negative emotions. Moreover, the psychological model 'Safewards' is focused on the explanation of people running away from health care centres through a wide range of conflicts (risk factors) and contentious behaviours (protection factors) which underlie runaway behaviours (Bowers, 2014).

Consequently, more is now known about the apparent socio-demographics of missing persons. Specifically, research has identified that a disproportionate number of missing person cases relate to children and young adults who are in substitute care; are reported missing repeatedly; have mental health issues; abuse alcohol/drugs; have experienced abuse, negligence or discrimination situations; have been victim of sexual exploitation; are having familial, scholar, emotional or delinquency problems; or are just want to be independent (Biehal et al., 2003; Blackmore et al., 2005; Foy, 2006, 2016; Gibb \& Woolnough, 2007; Shalev-Greene \& Hayden, 2014; Kiernan \& Henderson, 2002; Newiss, 2006; Tarling \& Burrows, 2004; Payne, 1995, Woolnough \& Cunningham, 2020; Crosland \& Dunlap, 2015; James et al., 2008; Kiepal et al., 2012; Morewitz, 2016; Shalev-Greene, 2011; Stevenson \& Thomas, 2018; Thompson et al., 2011; Tyler \& Cauce, 2002). In terms of adult cases, over-represented characteristics include males; mental health issues; judicial/police involvement; abuse from alcohol/drugs; and economic, labour, emotional and familial problems (Biehal, et al., 2003; Foy, 2006; Foy, 2016; Gibb \& Woolnough, 2007; Holmes, 2016; Newiss, 2004; Payne, 1995; Shalev-Greene \& Hayden, 2014; Tarling \& Burrows, 2004; Taylor, et al., 2018).

With these demographics in mind, some attempts have been made to classify missing person cases based on descriptively derived typologies. In the United Kingdom (UK), Payne (1995) classified missing person cases in five types: 'runaways', 'pushaways', 'throwaways', 'fallaways' and 'takeaways'. Using data from UK charitable organisations, Biehal et al. (2003) re-considered the disappearance as a 'missing continuum' which ranged from intentional to unintentional absences and differentiated four types: 'decided to leave', 'drifted', 'unintentionally absent' and 'forced to leave'. In Australia, Henderson et al. (2000) used police data to identify three typologies: 'those who leave to obtain independence or as a form of rebellion', 'those that disappear due to adverse consequences' and 'those that are lost involuntarily due to miscommunication or an accident'. Similarly, the Spanish National Centre of Missing Persons (CNDES) classifies cases into three groups based on law enforcement experience: 'intentional', 'unintentional' and 'forced' (Spanish Ministry of Interior, 2020).

There are just two studies that have contributed empirical knowledge in the form of multivariate-based typologies of missing person cases (Bonny et al., 2016; GarcíaBarceló et al., 2020a, b, c). Bonny et al. (2016) used smallest space analysis (SSA) to study the relations between thirty-six behaviours displayed by missing persons which were content analysed from $362 \mathrm{UK}$ police reports. They found that missing person reports in the UK could be classified under three different dominant themes 
('unintentional', 'dysfunctional' or 'escape'). In contrast, García-Barceló et al. (2020a, b, c) used multidimensional scaling (MDS) to study the relations between twenty-seven behaviours and circumstances content analysed from 341 missing person cases recorded by the police in Spain. In contrast to the Bonny et al. (2016) study which identified three themes, this study identified that intentional disappearances were best classified further with escape and dysfunctional subcategories. Consequently, the themes which best classified missing person reports in Spain were classified under four different dominant themes ('intentional-escape', 'intentional-dysfunctional', 'unintentional-accidental' and 'unintentional-forced').

Although the vast majority of people reported as missing are located within $24 \mathrm{~h}$ and in a relatively good state of health, a small percentage of cases (1-3\%) end in harm/fatal outcomes (Eales, 2017; Foy, 2006; Newiss, 2004; Spanish Ministry of Interior, 2021; Tarling \& Burrows, 2004). The ability to rapidly identify these cases, among such a large number of non-fatal/harmed cases, represents a critical operational policing challenge. However, the potential exists for the development of a research-led/evidence-based approach underpinned by statistically derived risk factors which could aid with the early identification of such cases potentially facilitate prevention of negative outcomes and optimise police investigations (García-Barceló et al., 2019).

Central to this is the expansion and testing of multivariate factors associated with missing person typologies/outcomes. For example, Bonny et al. (2016) found that young missing adults aged 30 years and below were more likely to go missing 'unintentionally', whereas those aged 31-60 years old were more likely to go missing as a means of 'escape' or for 'dysfunctional' reasons. Adults over 60 years old were more likely to go missing because of 'dysfunctional' reasons, followed by 'escape'. On the other hand, GarcíaBarceló et al. (2020a, b, c) found that going intentionally missing as a means of 'dysfunctional' reasons or unintentionally missing as a result of reasons 'accidental' was present in a higher proportion of males and adults. In contrast, going intentionally missing because of 'escape' was present in a higher proportion of females and minors. Going missing because of 'criminal' reasons was present in a higher proportion of females. Finally, missing persons that went intentionally missing as a means of 'escape' were found in a good state of health to a higher proportion, whereas those who went unintentionally missing as a means of 'accidental' were found to be harmed (but not deceased) to a higher proportion. In contrast, missing persons that went intentionally missing as a means of 'dysfunctional' were located deceased in a higher proportion. In addition, considering the missing person typology proposed by the Spanish Ministry of Interior ('intentional', 'unintentional' and 'forced'), García-Barceló et al. (2020a, b, c) found that going intentionally missing was present in a higher proportion of males, minors and nationals, whereas going forced missing was present in a higher proportion of females, adults and foreign nationals.

With specific regards to fatal outcomes, some international research has explored the socio-demographic variables which characterise missing person cases which result in harm/fatal outcomes (Eales, 2017; Newiss, 2006, 2011; Tarling \& Burrows, 2004). Some findings suggest that adults and elderly people are more likely to suffer fatal outcomes (Hayden and Shalev-Greene, 2018; Newiss, 2006). In Spain, García-Barceló et al. (2020a) found that being located in a good state of health was present in a higher proportion of minors, whereas being located harmed or deceased was present in a higher proportion of adults.

Importantly, while there is an evolving body of multivariate research in the UK and Australia, as discussed above, there is a critical absence of missing persons research from a European context where geographical boundaries between countries allow greater free 
movement. Consequently, the extent to which the findings of existing missing persons research can be applied across Europe is currently unknown.

In summary, most of the empirical research that has been conducted in the scope of missing person cases has focused on the explanation of the phenomenon, the description of missing persons and disappearances, as well as the identification of risk factors of harm (Biehal et al., 2003; Bonny et al., 2016; Buckley, 2012; García-Barceló, et al., 2019; Huey \& Ferguson, 2020). However, the latter have largely been addressed from a bivariate approach, resulting in a lack of knowledge based on multivariate statistical analysis which generates implications for the future calibration and validation of risk assessment tools focused on the early estimation of (a) missing person outcomes (good state of health, harmed or deceased) and (b) missing person typologies (intentional, unintentional and forced; Blackmore et al., 2005; Foy, 2016; Henderson et al., 2000; Newiss, 1999).

\section{Objectives}

\section{Current Study}

Using a sample comprising all missing person cases recorded over a 1-year period on the Spanish law enforcement system PDyRH, this study aims to test (using bivariate and multivariate analyses) whether key distinguishing missing person variables are statistically associated with typology and outcome. Specifically, based on the existing literature in this area, it is hypothesised that socio-demographic missing person characteristics (gender, age and nationality) can statistically distinguish different missing person typologies and outcomes (see Tables 1 and 2).

\section{Methods}

\section{Data Collection}

PDyRH system of CNDES is used by law enforcement in Spain to record information about missing persons, cadavers and unidentified human remains, facilitating automatic

Table 1 Hypothesised sociodemographic variables related to missing person typology

\begin{tabular}{lll}
\hline Typology & Distinguishing variables & Reference \\
\hline Voluntary & Males & 2,4 \\
& Minors & $2,4,6$ \\
& Adults over 60 years & 1 \\
Involuntary & Nationals & 2 \\
Forced & Young adults & 1,8 \\
& Females & $2,4,6,7$ \\
& Adults & 2,3 \\
& Foreigners & 2,5 \\
\hline
\end{tabular}

1, Bonny et al. (2016); 2, García-Barceló et al. (2020a, b, c); 3, Newiss (2006); 4, Foy (2016); 5, Newiss (2011); 6, Foy (2006); 7, Newiss (2004); 8, Eales (2017) 
Table 2 Hypothesised socio-demographic variables related to the missing person's state of health when located

\begin{tabular}{lll}
\hline State of health when located & Distinguishing variables & Reference \\
\hline Good state of health & Minors & $3,8,9$ \\
& Females & 9 \\
Injured & Females & 9 \\
& Adults & 9,10 \\
Deceased & Adults & $1,2,3,4,5,9$ \\
& Elderly adults & 1,2 \\
& Foreigners & 4 \\
& Males & $4,5,6,7,9,10$
\end{tabular}

1, Hayden and Shalev-Greene (2018); 2, Newiss (2006); 3, García-Barceló et al. (2020a); 4, Newiss (2011); 5, Foy (2016); 6, Yong \& Tzani-Pepelasis (2019); 7, Gibb \& Woolnough (2007); 8, Biehal et al. (2003); 9 , Perkins \& Roberts (2011); 10, Eales (2017)

comparison between cases. There is one record for each case, created by the police officers who investigate the case (Spanish Ministry of Interior, 2021). A dataset comprising all missing person records across the whole of Spain registered in the PDyRH system for a 1-year period (from January 1, 2019, to December 31, 2019) was electronically extracted $(n=24,284)$. The dataset was then refined based on the following inclusion and exclusion criteria: (a) solved cases were included $(n=21,237)$, but (b) unaccompanied foreigner minors' cases $(n=5,214 ; 21.47 \%)$, and (c) repeat cases were excluded $(n=7,194$; $29.62 \%$ ). Unaccompanied foreigner minors were identified in the sample via a specific preexisting variable for this group. However, as there was no pre-existing variable for repeat missing person incidents, such cases were identified via content analysis using key characteristics for cross-matching (i.e. name, surname and date of birth). From these repeat cases, only the first chronological case was included. These exclusion criteria were adopted to avoid biasing the data. In addition, considering the specific characteristics of unaccompanied foreigner minors and repeat missing person cases, these need to be considered in specific, independent research. Consequently, the final sample comprised 12,307 missing person records which were used in the current study.

\section{Sample Characteristics}

The age range of missing persons was from 1 to 94 years old $(M=30.89$ years, $\mathrm{Mdn}=$ 20 years, $\mathrm{SD}=19.01)$. As can be seen in Table 3, $n=6,823(55.4 \%)$ missing persons were over the age of 18 years (legal age for classification as an adult in Spain), and $n=$ $5,484(44.6 \%)$ under the age of 18 years. In addition, $n=7,021(57 \%)$ cases were related to men and $n=5,277$ (42.9\%) related to women. Nationality was examined, with $n=9,894$ (80.4\%) cases related to nationals and $n=2,413$ (19.6\%) related to foreign nationals. It was possible to identify the state of health of the persons when located in 4,663 cases. Of these, $n=4,308(92.4 \%)$ cases traced in a good state of health, $n=235(1.9 \%)$ were psychologically and/or physically harmed (e.g. being disoriented, suffering a psychotic attack or having a broken leg) and $n=120$ (1\%) were found deceased. Regarding the nature of the disappearances, information about dominant typology was gathered in 1,677 cases, and revealed that $n=1,499(89.4 \%)$ related to voluntary cases, $n=159(9.5 \%)$ related to 
Table 3 Sample description ( $n$ $=12,307)$

\begin{tabular}{llllr}
\hline & Variable & Category & $n$ & $\%$ \\
\hline Missing person & Age & Adult $(\geq 18)$ & 6,823 & 55.5 \\
& & Minor $(<18)$ & 5,484 & 44.5 \\
& Gender* & Men & 7,021 & 57.1 \\
& & Women & 5,277 & 42.9 \\
& Nationality & National & 9,894 & 80.4 \\
& & Foreigner & 2,413 & 19.6 \\
& State of & Good state of health & 4,308 & 92.4 \\
& health when & Harmed & 235 & 5.0 \\
& located** & Deceased & 120 & 2.6 \\
Disappearance & Typology*** & Voluntary & 1,499 & 89.4 \\
& & Involuntary & 159 & 9.5 \\
& & Forced & 19 & 1.1 \\
\hline
\end{tabular}

${ }^{*}$ Not known in 9 cases; **not known in 7,644 cases; ***not known in 10,630 cases

involuntary cases and $n=19(1.1 \%)$ related to forced cases. Regarding statistical representativeness, this 1-year sample description reflects findings of previous CNDES annual statistical reports based on cases records registered in PDyRH since 2009 (219,425; Spanish Ministry of Interior, 2021).

\section{Coding}

The PDyRH dataset extraction resulted in a data matrix comprised of 18 open text variables and four numeric variables with information about three main dimensions: police codification of the case (state of the case, territorial and police demarcation and dates), characteristics of the missing person (gender, age, nationality, origin and the state of health when located) and characteristics of the case (motivation and typology). This dataset was refined obtaining one numeric variable (age), four nominal dichotomous variables (gender: male, female; unaccompanied foreign minors: yes, no; age group: adults, minors, and nationality: national, foreigner) and two nominal polytomous variables (typology: voluntary, involuntary, forced; and state of health when located: good state of health, harmed, deceased). The typology dependent variable, based on definitions employed by the Spanish Ministry of Interior (2019), defines (a) voluntary cases as those in which the person has gone missing due to his/her own decision without the direct influence of third parties. This category encompasses a wide and varied range of circumstances, including young people running away from home/substitute care, individuals missing from hospital and adults consciously seeking time away from home for varied reasons. (b) Involuntary cases are those in which the person goes missing due to circumstances relating to accidents, natural catastrophes or becoming disoriented/lost; and (c) forced cases are those in which the person goes missing because of the influence of third parties/criminality (e.g. homicides, parental abductions or minors expelled from home). This simple classification system is used by law enforcement in many countries to facilitate the clear distinction of suspicious cases involving criminality (i.e. abductions and homicides) from non-suspicious cases.

Data processing was conducted following ethical criteria adopted in previous research (see, García-Barceló et al., 2020a, b, c) published in the scope of the Missing Persons 
Project ICFS-CNDES. Under the requirements of the Spanish data protection regulation (Organic Law 3/2018 of December 5th on Data protection and guarantee of digital rights), the data were anonymously coded with an identification number. As with many police systems not designed for research purposes, the recording of certain pieces of information in the PDyRH system (e.g. missing person typology and state of health when located) is not compulsory within the PDyRH system, resulting in some missing data values in the dependent variables (see Table 3).

\section{Data Analysis}

Rstudio version 3.5.0 was used for data analysis. Age, gender and nationality were analysed as independent variables (predictors), whereas typology and missing person state of health when located were analysed as dependent variables. Firstly, bivariate descriptive analyses were conducted using contingency tables. Secondly, ANOVA test and odds ratio (OR) were used to investigate the relations between socio-demographic variables, missing's person typology and state of health. Finally, multivariate inferential analyses based on multinomial logistic regression were conducted to determine the statistical significance of the effects.

\section{Results}

\section{Bivariate Analysis}

Age significantly differs between different types and outcomes of missing person cases ( $F=91.102, p<.000 ; F=278.067, p<.000$, respectively). With regard to the relationship between missing person age and typology $(n=1,677)$, post hoc comparisons using the Tukey test indicate that people who were involuntarily missing were older than people who were voluntarily missing or were forced missing ( $t=19.290, p<.000 ; t=30.066, p<.000$ ). People who were voluntarily missing were also older than people who were missing under the influence of third parties $(t=10.776, p<.000)$. When analysing those cases in which the missing person's state of health when located was known $(n=4,663)$, the results of Tukey test indicate that individuals located deceased were older than those traced harmed or in good state of health (labelled GSH in subsequent tables; $t=6.794, p<.001 ; t=26.078$, $p<.000)$. Individuals located harmed were also older than individuals located in good state of health $(t=19.284, p<.000$; see Table 4$)$.

Table 4 Descriptive comparison of age in missing person's typology and state of health when located $(n=$ $1,677 ; n=4,663)$

\begin{tabular}{llllllll}
\hline & & Mean & Mdn & SD & $\mathrm{Q}_{1}$ & $\mathrm{Q}_{2}$ & $\mathrm{Q}_{3}$ \\
\hline Typology & Voluntary & 28 & 17 & 17.26 & 16 & 17 & 40 \\
& Involuntary & 47.28 & 46 & 20.48 & 32 & 46 & 62 \\
& Forced & 17.21 & 10 & 18.41 & 4 & 10 & 21 \\
\multirow{3}{*}{ State of health } & GSH & 26.40 & 17 & 16.70 & 15 & 17 & 35.25 \\
& Harmed & 45.60 & 45 & 17.82 & 32 & 45 & 56 \\
& Deceased & 52.48 & 52 & 17.05 & 41.25 & 52.50 & 65 \\
\hline
\end{tabular}


While the distribution of missing person typology across gender did not reveal a difference, there were differences in terms of nationality. Specifically, the percentage of voluntary disappearances was higher for Spanish nationals than for foreign nationals, and foreign nationals showed a higher rate of involuntary and forced disappearances (see Table 5). In addition, Table 5 shows the distribution of missing person's state of health across gender and nationality. As can be seen, the percentage of females that were found in a GSH was somewhat higher than the percentage of males, whereas men showed a higher rate of harmed and deceased outcomes. In contrast, almost no differences were identified between nationals and foreign nationals (see Table 5).

The associations between missing person's socio-demographic variables and missing person's typology were studied using OR. In voluntary cases, the OR ranged from 2.93 for nationality and 8.30 for age group. For involuntary cases, the OR obtained ranged from 2.11 for nationality and 23.01 for age group. Finally, in forced cases, a significant OR was only identified for nationality (3.20; see Table 6). In terms of associations between missing person socio-demographic variables and state of health when located, where the missing person was located in a GSH, the OR ranged from 1.38 for gender to 68.30 for age. For harmed outcomes, the OR ranged from 1.58 for gender to 64.54 for age. Finally, for fatal outcomes, the OR ranged from 1.99 for gender to 62.61 for age (see Table 6).

\section{Multivariate Analysis}

Multinomial logistic regression analysis was conducted to test the hypothesised inter-play between variables. Typology and state of health were regressed on the three main sociodemographic variables identified from the existing literature (age, gender and nationality; see Table 1). The interactions between age, nationality and gender were calculated to determine the simplest multinomial regression model as well as to determine whether the association between two variables could change depending on other variables. First, the model was analysed by including all the interactions between the three independent variables. Then, the non-significant interactions were eliminated and a second model was created using the significant coefficients identified in the full-interaction model. All interactions between age, nationality and gender were found to be non-significant in the first model

Table 5 Descriptive comparison of gender and nationality in missing person's typology and state of health when located $(n=1,677 ; n=4,663)$

\begin{tabular}{|c|c|c|c|c|c|c|c|c|c|}
\hline \multirow[t]{3}{*}{ Variable } & \multirow[t]{3}{*}{ Category } & \multicolumn{4}{|c|}{ Gender $^{1,2}$} & \multicolumn{4}{|c|}{ Nationality } \\
\hline & & \multicolumn{2}{|c|}{ Female } & \multicolumn{2}{|l|}{ Male } & \multicolumn{2}{|c|}{ Foreigner } & \multicolumn{2}{|c|}{ National } \\
\hline & & $n$ & $\%$ & $n$ & $\%$ & $n$ & $\%$ & $n$ & $\%$ \\
\hline \multirow[t]{3}{*}{ Typology $^{1}$} & Voluntary & 615 & 90.0 & 880 & 88.9 & 213 & 81.3 & 1286 & 90.9 \\
\hline & Involuntary & 60 & 8.8 & 99 & 10.0 & 42 & 16.0 & 117 & 8.3 \\
\hline & Forced & 8 & 1.2 & 11 & 1.1 & 7 & 2.7 & 12 & 0.8 \\
\hline \multirow[t]{3}{*}{ State of health ${ }^{2}$} & GSH & 1917 & 94.2 & 2387 & 91.0 & 746 & 91.5 & 3562 & 92.6 \\
\hline & Harmed & 85 & 4.2 & 149 & 5.7 & 49 & 6.0 & 186 & 4.8 \\
\hline & Deceased & 34 & 1.6 & 86 & 3.3 & 20 & 2.5 & 100 & 2.6 \\
\hline
\end{tabular}

${ }^{1,2}$ Only known in 1,673 and 4,658 cases, respectively 
Table 6 Socio-demographic odds ratio for missing person's typology and state of health when located $(n=$ $1,677 ; n=4,663)$

\begin{tabular}{|c|c|c|c|c|c|}
\hline \multicolumn{3}{|l|}{ Variable } & \multirow{2}{*}{$\begin{array}{l}\text { Age } \\
\begin{array}{l}8.30[5.15, \\
13.36]^{* * * *}\end{array}\end{array}$} & \multirow{2}{*}{$\begin{array}{r}\text { Nationality } \\
2.93[1.60, \\
3.28]^{* * *}\end{array}$} & \multirow{2}{*}{$\begin{array}{l}\text { Gender } \\
0.88[0.64,1.21]\end{array}$} \\
\hline Typology & Voluntary & OR. $95 \%$ CI & & & \\
\hline & & $\left(\chi^{2}\right)$ & 102.19 & 21.41 & 0.56 \\
\hline & Involuntary & OR. $95 \% \mathrm{CI}$ & $\begin{array}{c}23.01[10.71 \\
49.41] * * *\end{array}$ & $\begin{array}{r}2.11[1.44, \\
3.09]^{* * *} *\end{array}$ & $1.15[0.82,1.61]$ \\
\hline & & $\left(\chi^{2}\right)$ & 127.88 & 15.51 & 0.69 \\
\hline & Forced & OR. $95 \% \mathrm{CI}$ & $0.40[0.15,1.07]$ & $3.20[1.25,8.23]^{*}$ & $0.94[0.37,2.36]$ \\
\hline & & $\left(\chi^{2}\right)$ & 3.54 & 6.56 & 0.13 \\
\hline \multirow[t]{6}{*}{ State of health } & GSH & OR. $95 \% \mathrm{CI}$ & $\begin{array}{r}68.38[30.64 \\
154.62]^{* * *}\end{array}$ & $1.15[0.87,1.51]$ & $1.58[1.26,1.99]^{* * *}$ \\
\hline & & $\left(\chi^{2}\right)$ & 361.75 & 1.02 & 15.86 \\
\hline & Harmed & OR. 95\% CI & $\begin{array}{r}64.54[23.79 \\
173.73]^{* * *}\end{array}$ & $0.79[0.57,1.09]$ & $1.38[1.05,1.81]^{*}$ \\
\hline & & $\left(\chi^{2}\right)$ & 232.86 & 1.95 & 5.46 \\
\hline & Deceased & OR. $95 \% \mathrm{CI}$ & $\begin{array}{r}62.61[15.49 \\
253.61]^{* * *}\end{array}$ & $1.06[0.65,1.72]$ & $1.99[1.33,2.98]^{* * *}$ \\
\hline & & $\left(\chi^{2}\right)$ & 116.07 & 0.56 & 11.83 \\
\hline
\end{tabular}

OR, odds ratio; CI 95\%

Significant value $(r)$ for risk $* p<.05, * * p<.01,{ }^{* * *} p<.001$

(the lowest $p$ value for any interaction coefficient was $p=.156$ ). Thus, the second model includes only the main effects of the independent variables.

Regarding typology, the regression equation (with main effects only) was significant: $\chi^{2}=167.707, p<.000$, with a pseudo- $R^{2}$ of .18 which is low effect (see Table 7). The estimated coefficients for this multinomial regression model mean that the rate of involuntary

Table 7 Multinomial logistic regression coefficients for missing person's typology $(n=1,677)$

\begin{tabular}{llll}
\hline Predictors & $B(S E)$ & Odds ratios & $95 \%$ CI [lower, upper] \\
\hline Involuntary vs. voluntary & & & \\
$\quad$ Intercept & $-3.16(0.25)^{* * *}$ & & \\
$\quad$ Age (numeric) & $0.04(0.00)^{* * *}$ & 1.04 & {$[1.04,1.05]$} \\
$\quad$ Gender $(1=$ male) & $-0.16(0.18)$ & 0.85 & {$[0.59,1.22]$} \\
$\quad$ Nationality $(1=$ nationals) & $-0.91(0.21)^{* * *}$ & 0.40 & {$[0.26,0.60]$} \\
Forced vs. voluntary & $-1.75(0.72)^{*}$ & & \\
$\quad$ Intercept & $-0.08(0.03)^{* *}$ & 0.91 & {$[0.86,0.98]$} \\
$\quad$ Age (numeric) & $0.26(0.47)$ & 1.29 & {$[0.51,3.28]$} \\
Gender $(1=$ male) & $-1.29(0.48)^{* *}$ & 0.27 & {$[0.10,0.70]$} \\
$\quad$ Nationality $(1=$ nationals $)$ & & & \\
\hline
\end{tabular}

Voluntary, base category; $S E$, standard error; $C I$, confidence interval; significance $=* * * p<0.001$, ** $p<$ $0.01, * p<0.05 . \chi^{2}=169.472 . p=.000 ;$ Cox and Sell's $R^{2}=.09$; Nagelkerke's $R^{2}=.18 ;$ McFadden's $R^{2}=$ .13 
and forced disappearances increases faster in relation to age than the rate of voluntary disappearances. In addition, Spanish national missing persons were less likely to go involuntarily missing or be forced missing than foreign nationals (see Table 7).

Figure 1 shows the distribution of typology for each age to facilitate the interpretation of the results of the multinomial logistic regression. As can be seen, the general trend is a decrease of voluntary cases and an increase of involuntary ones as age increases. Most of the cases were voluntary except for advanced age, which were mainly involuntary, and for forced disappearances, which were mainly concentrated in the minor age group. For those persons who were between 0 and 20 years old, the likelihood of going voluntary or involuntary missing changes little. However, for those persons who were older than 20 years old, the likelihood of going involuntary missing increases steadily with age and is predominant for individuals above 75 years old.

On the other hand, a multinomial regression was calculated to predict the missing person's state of health when located based on missing person's age, nationality and gender. A significant regression equation was found for missing person's state of health when located $\left(\chi^{2}=387.018, p<.000\right)$, with a pseudo- $R^{2}$ of .17 which was found to be low effect. The estimated coefficients for this multinomial regression model imply that the older the missing person is the more likely they are to be located harmed or deceased (see Table 8).

Figure 2 shows the distribution of state of health when located as a function of age. The general trend shows that most disappearances result in GSH for all age groups. However, the probability of a GSH decreases as age increases. In addition, although harmed and deceased outcomes increase with age, there are more missing persons which result in harm than deceased.

\section{Discussion and Conclusions}

The current research explored socio-demographic differences in Spanish missing person's typology and state of health when located, to identify early indicators of persons at risk of being forced missing and located harmed or deceased. The results show that socio-demographic factors, specifically missing person's age, can differentiate between missing person types (voluntary, involuntary and forced cases) and state of health when located (good state of health, harmed and deceased).

Fig. 1 Multinomial logistic regression of typology as a function of age

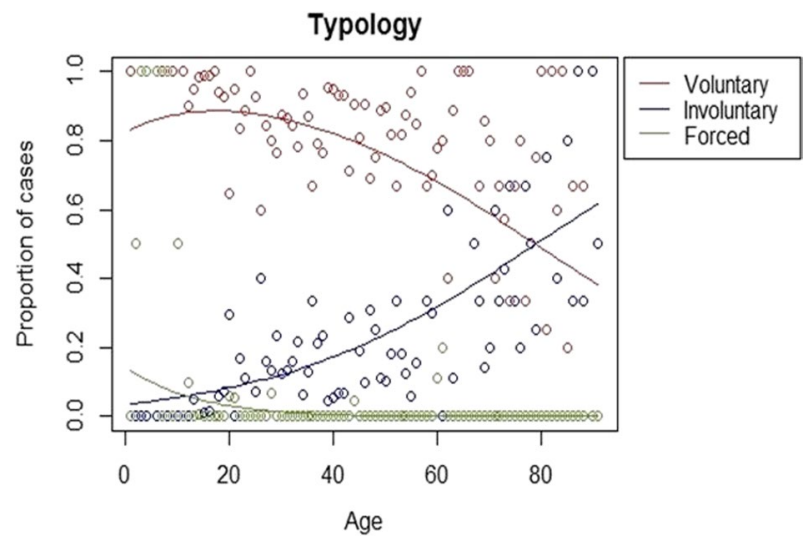


Table 8 Multinomial logistic regression coefficients for missing person's state of health when located $(n=$ 4,663)

\begin{tabular}{llll}
\hline Predictors & $B(S E)$ & Odds ratios & 95\% CI [lower, upper] \\
\hline Harmed vs. GSH & & & \\
$\quad$ Intercept & $-4.43(0.21)^{* * *}$ & & \\
$\quad$ Age (numeric) & $0.04(0.00)^{* * *}$ & 1.04 & {$[1.04,1.05]$} \\
$\quad$ Gender $(1=$ male $)$ & $0.06(0.14)$ & 1.06 & {$[0.80,1.41]$} \\
$\quad$ Nationality $(1=$ nationals) & $-0.19(0.17)$ & 0.82 & {$[0.59,1.15]$} \\
Deceased vs. GSH & & & \\
Intercept & $-6.11(0.34)^{* * *}$ & & \\
Age (numeric) & $0.05(0.00)^{* * *}$ & 1.06 & {$[1.05,1.07]$} \\
$\quad$ Gender (1 = male) & $0.38(0.21)$ & 0.96 & {$[0.96,2.22]$} \\
$\quad$ Nationality (1 = nationals) & $0.06(0.25)$ & 0.64 & {$[0.64,1.76]$} \\
\hline
\end{tabular}

Good state of health (GSH), base category; SE, standard error; $C I$, confidence interval; significance $=* * *$ $p<0.001, * * p<0.01, * p<0.05 \cdot \chi^{2}=391.238 . p=.000$; Cox and Sell's $R^{2}=.08$; Nagelkerke's $R^{2}=.17$; McFadden's $R^{2}=.13$

Fig. 2 Multinomial logistic regression of state of health when located as a function of age

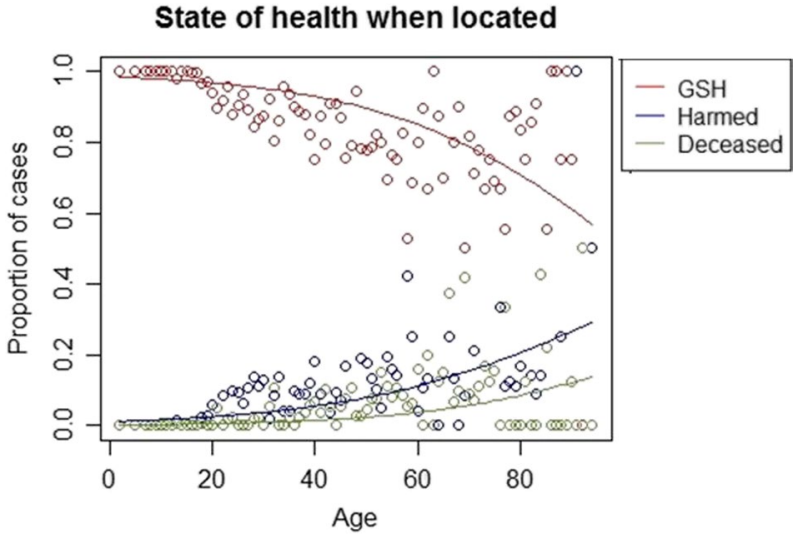

With regard to typology, Spanish nationals were more likely to go intentionally missing in contrast to foreign nationals who were more likely to go unintentionally or forced missing. Furthermore, minors were more likely to be forced missing whereas adults were more likely to go intentionally missing. Regarding gender, multinomial regression results were not significant for this variable.

While these results are partially supportive of previous research in this field, there are some interesting differences (Bonny et al., 2016; Eales, 2017; Foy, 2006; García-Barceló et al., 2020a, b, c; Newiss, 2004, 2006). UK and Australian research suggests the profile of those persons who go intentionally (or voluntarily) missing is mainly characterised by being male, minor and national (Bonny et al., 2016; Foy 2006, 2016). However, the results of this Spanish-based research indicate that being national is the item which best characterises voluntary missing persons. Furthermore, while previous Australian research has identified males as more likely to go missing intentionally (Foy, 2016), the results of this research identified that the number of males and females intentionally missing in Spain was actually very similar (90\% vs. $89 \%$ ). With regard to age, whereas minors have been found 
to be the main age group intentionally going missing in Australia (Foy, 2006, 2016), the results of this research found that Spanish adults go intentionally missing in a higher proportion than Spanish minors, although the latter are forced missing in a higher proportion than adults. This facet could be related to the fact that it is not compulsory to record some information about missing person's cases in PDyRH system. Thus, the vast majority of forced cases recorded in PDyRH relate to non-violent parental abductions (as indicated in Baker et al., 2002) whereas forced missing person cases which relate to violent crimes (e.g. homicide or sexual assault) are not recorded in PDyRH.

With regard to people who go unintentionally missing, UK research identified that young adults were more likely to go unintentionally missing (Bonny et al., 2016; Eales, 2017), whereas the research findings presented here identified that persons involved in involuntary Spanish missing person cases were older than those related to voluntary cases. In addition, although there are no significant findings in UK and Australian research about the relations between nationality and going unintentionally missing, these research findings identified that foreign nationals (non-Spanish nationals) were more likely to go unintentionally missing. Qualitatively, these findings could be explained by the fact that a large number of foreign nationals (non-Spanish) reported missing in Spain have experienced a drift (absence of contact) situation from their nearest environments or different kinds of accidents and may speak to the influence of free borders on the movement of missing person in Spain in contrast to the UK and Australia. In contrast, UK, Australian and Spanish findings showed that sex was not significant when assessing the likelihood of going unintentionally missing. Finally, the existing Australian and UK research suggests that the main profile of people who are forced missing is being male, adult and foreigner (Foy, 2006, 2016; Newiss, 2004, 2006; Newiss, 2011). In this manner, the existing findings are similar to the ones identified in the present research which suggests that foreign nationals (non-Spanish) are more likely to go forced missing than nationals. In contrast, whereas UK research found an association between being adult and going forced missing (Newiss, 2004), minors reported as missing in Spain were more likely to go forced missing than adults, which could be explained by the aforementioned facet related to PDyRH coding duties. Finally, gender studied in this Spanish sample did not demonstrate clear implications for early assessment of the likelihood of belonging to one missing person type.

With regard to the second hypothesis, minors were more likely to be traced in a good state of health, whereas adults and specifically elderly people were more likely to be located harmed or deceased. These results are consistent with the hypothesis (Biehal, Mitchell \& Wade, 2003; Eales, 2017; Foy, 2016; García-Barceló et al., 2019; Gibb \& Woolnough, 2007; Hayden and Shalev-Greene, 2018; Newiss, 2006, 2011; Perkins \& Roberts, 2011; Yong \& Tzani-Pepelasis, 2019; see Table 2). Regarding gender and nationality, multinomial regression results were not significant for these variables.

Comparing these findings with those found in the UK context, they seem to indicate that age is the best socio-demographic characteristic which could early identify the risk of harm and fatal outcomes. In this regard, it could be concluded that being an adult could be considered a risk factor for being located harmed or deceased, both in a UK and Spanish context (Biehal et al., 2003; Eales, 2017; Foy, 2016; García-Barceló et al., 2019; Gibb \& Woolnough, 2007; Hayden and Shalev-Greene, 2018; Newiss, 2006, 2011; Perkins \& Roberts, 2011; Yong \& Tzani-Pepelasis, 2019). Essentially, the older the missing person is, the higher the risk of harm or a fatal outcome.

Regarding nationality, the study of this variable has produced controversies and research, especially related to racial bias in missing person appeals (Peebles, 2021; Slakoff $\&$ Fradella, 2019; Sommers, 2016). The scope of this research focused on the identification 
of a relationship between missing person nationality and state of health when located. While UK findings showed the distribution of foreigner nationals was higher for those missing person cases which result in a fatal outcome (Newiss, 2011), this research did not identify relations between these two facets, with the distribution of Spanish nationals and foreign nationals very similar (2.5 vs. 2.6 respectively) when studying fatal outcomes.

Finally, although UK research (Perkins \& Roberts, 2011) found that the distribution of females was higher in those cases in which the person is located in a good state of health or harmed, this research did not indicate any significant relationship between sex and being located harmed (females 4.2 vs. males 5.7). In the same way, some UK and Australian authors (Eales, 2017; Foy, 2016; Gibb \& Woolnough, 2007; Newiss, 2011; Perkins \& Roberts, 2011; Young \& Tzani-Pepelasis, 2019) concluded that males were more likely to be traced deceased. In contrast, the results from this research did not indicate any significant relation between the missing person's sex and being located deceased, although the distribution of sex was higher for males than females when studying fatal outcomes cases (3.3 vs. 1.6 respectively).

These findings suggest that despite the importance of sex from a descriptive point of view, nationality and age were found to be the socio-demographic factors which better classify missing person type and state of health when located. Some authors (e.g. Alys et al., 2013; Stewart, 2018) conclude that the missing persons' phenomenon is multifaceted. In this manner and trying to answer the question addressed in the title of this paper, the results of this research support the latter authors' ideas, suggesting that this phenomenon cannot be explained solely by socio-demographic variables. In this regard, it is necessary to conduct further research focused on identifying psychosocial, criminological and geographical risk indicators that help to classify, explain and distinguish between the missing person's typology and state of health when located, especially between suicide and homicide cases.

As discussed above, while the findings presented in this paper show some similarity with existing research, there are also clear differences. Essentially, existing quantitative research is based almost exclusively on UK and Australian samples, which may be vitally different to those observed in a mainland European context where cross-border movement is facilitated by the Schengen area which allows for a common visa policy and free movement across 26 different countries. Thus, while it would not be unreasonable to expect there to be commonalities in terms of missing person behaviour in the UK, Australia and mainland Europe, it is also likely that there will be key differences which may account for differences observed in this paper. Furthermore, there has been no attention paid to cultural influences in the field of missing persons and, as such, a wider European research base would allow for this.

\section{Implications for Practice}

As with the results of previous Spanish and international missing person's research (e.g. Eales, 2017; García-Barceló et al., 2020a, b, c; Gibb and Woolnough, 2007; Newiss, 2004, 2006), these findings favour the improvement of preventive initiatives and the standardisation of the first responders' actions.

In terms of prevention, these socio-demographic findings could offer preventive opportunities at educational, health and social care levels. Specifically, this knowledge provides information to those agencies working with vulnerable groups (e.g. identifying minors at risk of going missing from educational centres, risk of the elderly going missing from care or social services, among others), as well as promoting prevention campaigns focused on 
specific groups of people according to their socio-demographic and psychosocial characteristics. For instance, educational talks about 'strategies for the prevention of missing person cases' could be carried out in schools' programs focused on different groups of age and considering the specific characteristics of gender and origin. On the other hand, prevention guides and protocols could be developed and integrated in the context of social services as well as educational and mental health centres. Such interventions could favour the early identification of the people at risk of going missing in the future as well as the establishment of mechanisms which could prevent its occurrence.

In the scope of the first response of Law Enforcement Agencies (LEA's), especially in the context of implications for police investigations, the identification of risk factors of forced and fatal outcomes by age, generated by this research, will facilitate the creation of support tools which could improve the decision-making process using an evidenceinformed approach during missing person investigations. For instance, the creation and validation of different risk assessments of harm and fatal outcomes systems for adults and minors will favour a more effective police resource management with the main goals of accelerating the missing person search process and increasing the possibilities of locating the missing person in a good state of health. In addition, the creation of evidence-informed protocols for investigating missing person cases could be addressed considering the specific characteristics as the age, nationality or gender associated to each missing person type, thus favouring the early classification of the cases once that they have been reported to police agencies. In this manner, different investigative lines of enquiry could be established for the investigation of each missing person type. Such initiatives would facilitate the prioritisation of appropriate cases (i.e. forced cases and those related to a possible harmed or deceased outcome, especially suicides and homicides) as well as the reduction of the psychological impact derived from those missing person cases in which the police investigation remains active. Importantly, at a European and international level, understanding variation in missing persons characteristics and risks across countries is important for the effective role of Interpol when issuing Yellow Notices as a global police alert for a missing person. These Notices are issued for victims of parental abductions, criminal abductions (kidnappings) or unexplained disappearances to increase the chances of a missing person being located, particularly if there is a possibility that the person might travel, or be taken, abroad. Consequently, understanding and identifying risk of harm at a national and transnational level is central to this process. Arguably, without a richer understanding of how missing person cases compare within and across European countries, the effectiveness of such processes is not maximised.

\section{Limitations and Future Research}

The findings of this research suggest that there are specific socio-demographic factors, specifically age, that can influence why and how a person becomes missing and the outcome of their case. In this regard, although regression equations were significant, they were found to be low effect, suggesting that age is a modulating variable in the missing persons' phenomenon. Considering the importance of age in the explanation of the missing person's phenomenon, these findings further highlight two main facets: (a) the need for establishing more research focused on identifying other psychosocial, criminological and geographical risk factors, and (b) the need for research to consider specific sub-groups of age-minors (0-12 years old, 13-17 years old) and adults (18-60 years old, older than 60 years old). 
Although the representativeness of the sample used in this study could be ensured, the main limitation of this research was the amount of missing data regarding the dependent variables. This was due to the absence of a requirement to record certain information in the PDyRH system. Furthermore, there is a need for in-depth review of those missing persons' cases which are not recorded in PDyRH but concur with violent crimes, such as homicides, child exploitation, human trafficking or sexual assaults. This issue predominantly relates to the fact that the police data utilised were not originally collected for the purpose of conducting research, which generated discrepancies in the overall validity and quality of the data. Specifically, there was a lack of psychosocial data that could allow more detailed analysis. However, the use of police data in this field is acknowledged and has been successfully used in previous research (Bonny et al., 2016; Canter \& Alison, 2003; García-Barceló et al., 2020a, b, c; Palermo \& Kocsis, 2005; Sotoca et al., 2013). In addition, considering the special characteristics of missing unaccompanied foreigner minors and repeat missing persons mentioned above, there is a need for future research to consider these specific groups. Finally, there may be a limitation associated with only using an intentional/unintentional spectrum, based on police recorded information, to define missing person typologies. Utilising data collected from return interviews with former missing persons could facilitate the identification of a richer picture of motives which could lead to the person going missing.

Future research needs to replicate the research presented in this paper using psychosocial, criminological and geographical missing persons' data that will favour the identification of risk factors of forced cases, as well as harmed and violent deceased outcomes (suicides and homicides) in adults and minors. This will facilitate the validation and calibration of a structured professional judgment (SPJ) risk assessment system and decision support tool which will support law enforcement's initial response when dealing with missing person's cases as well as the development of specific preventive initiatives based on psychosocial, socio-demographic, criminological and geographic factors.

In conclusion, this research has produced empirical knowledge about the relations between the socio-demographic characteristics of missing persons in Spain and their typology and state of health when located, which may contribute to the early classification of missing person cases reported to law enforcement. Critically, this paper also calls for wider European-based research on missing persons, to allow for the establishment of a European comparative perspective and informed research base on this neglected but important issue.

Acknowledgements The authors extend sincere thanks to the Spanish National Centre of Missing Persons and the General Direction for Coordination and Research of the Spanish Secretary of State for Security of the Spanish Ministry of Interior.

Funding Open Access funding provided thanks to the CRUE-CSIC agreement with Springer Nature. This study was partially supported by a grant provided by Ministry of Science, Innovation and Universities (MCIU) of the Spanish Government, RTI2018-101167-B-I00 (MCIU/AEI/FEDER, UE): 'Risk factors and psychosocial adjustment in online child grooming: A longitudinal study'.

Availability of Data and Material The data that support the findings of this study are available from the date base 'Personas Desaparecidas y Restos Humanos sin Identificar' (PDyRH) which belongs to the Spanish National Center for Missing Persons, dependent on the Spanish Ministry of Interior, but restrictions apply to the availability of these data. The data were used under license for the current study, and so are not publicly available. 


\section{Declarations}

Ethics Approval This article does not contain any studies with human participants or animals performed by any of the authors.

Conflict of Interest The authors declare no competing interests.

Open Access This article is licensed under a Creative Commons Attribution 4.0 International License, which permits use, sharing, adaptation, distribution and reproduction in any medium or format, as long as you give appropriate credit to the original author(s) and the source, provide a link to the Creative Commons licence, and indicate if changes were made. The images or other third party material in this article are included in the article's Creative Commons licence, unless indicated otherwise in a credit line to the material. If material is not included in the article's Creative Commons licence and your intended use is not permitted by statutory regulation or exceeds the permitted use, you will need to obtain permission directly from the copyright holder. To view a copy of this licence, visit http://creativecommons.org/licenses/by/4.0/.

\section{References}

Alys, L., Massey, K., \& Tong, S. (2013). Investigative decision making: Missing people and sexual offences, crossroads to an uncertain future. Journal of Investigative Psychology and Offender Profiling, 10(2), 140-154. https://doi.org/10.1002/jip.1382

Association of Chief Police Officers. (2013). Interim guidance on the management, recording and investigation of missing persons. College of Policing.

Baker, T., Burgess, A. W., Rabun, J. B., Jr., \& Nahirny, C. (2002). Abductor violence in nonfamily infant kidnapping. Journal of Interpersonal Violence, 17(11), 1218-1233.

Biehal, N., Mitchell, F., \& Wade, J. (2003). Lost from view: Missing persons in the UK. Policy Press.

Blackmore, K., Bossomaier, T., Foy, S., \& Thomson, D. (2005). Data mining of missing persons data. In Classification and Clustering for Knowledge Discovery (pp. 305-314). Springer.

Bonny, E., Almond, L., \& Woolnough, P. (2016). Adult missing persons: Can an investigative framework be generated using behavioural themes? Journal of Investigative Psychology and Offender Profiling, 13(3), 296-312. https://doi.org/10.1002/jip.1459

Bowers, L. (2014). Safewards: A new model of conflict and containment on psychiatric wards. Journal of Psychiatric and Mental Health Nursing, 21(6), 499-508. https://doi.org/10.1111/jpm.12129

Buckley, M. (2012). Towards more effective missing women investigations: Police relationships with victims" families, the community and the media. Report of the Missing Women Commission of Inquiry

Canter, D., \& Alison, L. J. (2003). Converting evidence into data: The use of law enforcement archives as unobtrusive measurement. The Qualitative Report, 8(2), 151-176.

College of Policing. (2021). Missing Persons: Major investigation and public protection. Retrieved from: https://www.app.college.police.uk/app-content/major-investigation-and-public-protection/missingpersons/

Crosland, K., \& Dunlap, G. (2015). Running away from foster care: What do we know and what do we do? Journal of Child and Family Studies, 24, 1697-1706. https://doi.org/10.1007/s10826-014-9972-X

Eales, N. (2017). Risky business? A study exploring the relationship between harm and risk indicators in missing adult incidents (PhD Thesis). University of Portsmouth

European Union. (2009). Recommendation CM/Rec (2009/12) on principles concerning missing persons and the presumption of death. European Council. December, $9^{\text {th }}, 2009$. pp. 5-24.

Ferguson, L., \& Soave, V. (2020). \#Missing to \#Found: Exploring police Twitter use for missing persons investigations. Police Practice and Research, 21. https://doi.org/10.1080/15614263.2020.1753516

Foy, S. (2006). Profiling missing persons within New South Wales (PhD thesis). Charles Sturt University

Foy, S. (2016). A profile of missing persons: Some key findings for police officers. En S.J. Morewitz, C. Sturdy Colls (Eds.), Handbook of Missing Persons (p. 718). Springer

Fyfe, N., Parr, H., Stevenson, O., \& Woolnough, P. (2015). To the end of the world: Space, place, and missing persons investigations. Policing: a Journal of Policy and Practice, 9(3), 275-283. https://doi.org/ 10.1093/police/pav025 
García-Barceló, N., González Álvarez, J.L., \& Cereceda Fernández-Oruña. (2020a). Personas Desaparecidas: un estudio piloto de casos [Spanish Missing persons: a pilot study of cases]. Centro Nacional de Desaparecidos, Ministerio del Interior

García-Barceló, N., González Álvarez, J.L., Ortigosa Juárez, A., \& Cereceda Fernández-Oruña. (2020b). Desapariciones con desenlace fatal de etiología homicida en España [Spanish missing person cases which result in homicide outcome]. Centro Nacional de Desaparecidos, Ministerio del Interior

García-Barceló, N., González-Álvarez, J. L., Almond, L., \& Woolnough, P. (2020). Behavioural themes in Spanish missing person cases: An empirical typology. Journal of Investigative Psychology and Offender Profiling, 17(3), 349-364. https://doi.org/10.1002/jip.1562

García-Barceló, N., Tourís-López R. M. \& González-Álvarez, J. L. (2019). Personas desaparecidas: conveniencia de fomentar la investigación científica en España [Missing persons: convenience of promoting research in Spain]. Boletín Criminológico, 25, 1-13.

Gibb G., \& Woolnough, P. (2007). Missing persons: Understanding, planning, responding - a guide for police officers. Grampian Police

Gong, X. D., Cheng, H., Yang, L., Duan, Y. M., Yao, Y., Feng, Y. F., Fu, L., Liu, J. H., \& Du, M. Y. (2017). Analysis of geographical distribution of missing children based on the missing children mobile GIS Mutual Assistance System of China. Journal of Geoscience and Environment Protection, 5, 117-134.

Hayden, C., \& Shalev-Greene, K. (2018). The blue light social services? Responding to repeat reports to the police of people missing from institutional locations. Policing and society, 28(1), 45-61.

Henderson, M., Henderson, P., \& Kiernan, C. (2000). Missing persons: Incidence, issues and impacts. Australian Institute of Criminology, 144, 1-6.

Holmes, L. (2016). Intentionality and missing adults. In K. Shalev Greene \& L. Alys (Eds.), Missing Persons: A Handbook of Research (pp. 91-98). Routledge.

Huey, L., \& Ferguson, L. (2020). 'Going Missing' as a maladaptive coping behavior for adults experiencing strain. Deviant Behavior, 43(1), 17-29. https://doi.org/10.1080/01639625.2020.1773175

James, M., Anderson, J., \& Putt, J. (2008). Missing persons in Australia. Trends and issues in crime and criminal justice (No. 353). Australian Institute of Criminal Justice

Kiepal, L., Carrington, P., \& Dawson, M. (2012). Missing persons and social exclusion. Canadian Journal of Sociology, 37, 137-168. https://doi.org/10.29173/cjs10114

Kiernan, C., \& Henderson, M. (2002). Missing persons: Extending traditional policing boundaries to address a social issue. Paper to Third Australasian women and policing conference: women and policing globally, 2-23.

Lampinen, J. M., Arnal, J., \& Hicks, J. L. (2009). The effectiveness of supermarket posters in helping to find missing children. Journal of Interpersonal Violence, 24(3), 406-423.

Ley Orgánica 3/2018, de 5 de diciembre, de Protección de Datos Personales y garantía de los derechos digitales [Organic Law 3/2018, of December $5^{\text {th }}$, on the Protection of Personal Data and guarantee of digital rights]. Boletín Oficial del Estado, 294, de 6 de diciembre de 2018. https://www.boe.es/eli/es/ 1o/2018/12/05/3

Morewitz, S. (2016). Runaway and homeless youth: New research and clinical perspective. Springer International Publishing. https://doi.org/10.1007/978-3-319-30863-0

National Crime Agency and UK Missing Persons Bureau. (2016). Missing persons Data Report 2014/2015. London: NCA. Retrieved from: file://C:/Users/usuario/Downloads/201415\%20Full\%20Final\%20 Missing\%20Persons\%20Data\%20Report\%201.0\%2020 160516\%20(NPM).pdf

National Crime Information Center - FBI (2017). Missing Person and Unidentified Person Statistics. Criminal Justice Information Service (CJIS). Retrieved from: https:/www.fbi.gov/services/cjis/cjis-link/ 2017-ncic-missing-personandunidentified-person-statistics

Newiss, G. (1999). Missing presumed...? The police response to missing persons. Police Research.

Newiss, G. (2004). Estimating the risk faced by missing persons: A study of homicide victims as an example of an outcome-based approach. International Journal of Police Science \& Management, 6(1), 27-36. https://doi.org/10.1350/ijps.6.1.27.34460

Newiss, G. (2006). Understanding the risk of going missing: Estimating the risk of fatal outcomes in cancelled cases. Policing: An International Journal of Police Strategies and Management, 29(2), 246260. https://doi.org/10.1108/13639510610667655

Newiss, G. (2011). Learning from fatal disappearances. A report by missing people. Missing People.

Palermo, G.B. \& Kocsis, R.N. (2005). Offender Profiling: An Introduction to the Sociopsychological Analysis of Violent Crime. Charles C. Thomas.

Payne, M. (1995). Understanding 'going missing': Issues for social work and social services. The British Journal of Social Work, 25(3), 333-348. https://doi.org/10.1093/oxfordjournals.bjsw.a056183

Peebles, C. (2021). Victim blame of missing people based on race and media framing. (Doctoral Thesis). University of Central Florida 
Sarkin, J. (2019). Why victimology should focus on all victims, including all missing and disappeared persons. International review of victimology, 25(2), 249-270.

Shalev-Greene, K. (2011). Children who go missing repeatedly and their involvement in crime. International Journal of Police Science and Management, 13(1), 29-36. https://doi.org/10.1350/ijps.2011. 13.1.197

Shalev-Greene, S. K., \& Hayden, F. (2014). The cost of missing person investigations: Implications for current debates. Policing: A Journal of Policy and Practice, 8(1), 27-34. https://doi.org/10.1093/police/ pat036

Shalev-Greene, K. S., Hayler, L., \& Pritchard, D. (2019). A house divided against itself cannot stand: Evaluating police perception of UK missing person definition. European Journal on Criminal Policy and Research, 1-17. https://doi.org/10.1007/s10610-019-09428-0

Slakoff, D. C., \& Fradella, H. F. (2019). Media Messages Surrounding Missing Women and Girls: The Missing White Woman Syndrome and Other Factors that Influence Newsworthiness. Criminology, Criminal Justice, Law \& Sociology, 20, 80.

Sommers, Z. (2016). Missing White Woman Syndrome: An Empirical Analysis of Race and Gender Disparities in Online News Coverage of Missing Persons. Journal of Criminal Law \& Criminology, 106. Retrieved from: https://scholarlycommons.law.northwestern.edu/jclc/vol106/iss2/4

Sotoca, A., González, J. L., Fernández, S., Kessel, D., Montesinos, O., \& y Ruiz, M. (2013). Perfil del incendiario forestal español: aplicación del perfilamiento criminal inductivo [Profile of the Spanish forest arsnoist: application of criminal profiling]. Anuario de Psicología Jurídica, 23, 1-8.

Spanish Ministry of Interior. (2020). Informe de Personas Desaparecidas -España [Missing Persons Report- Spain]. Retrieved from: http://www.interior.gob.es/documents/10180/11389243/Informe+ Personas+Desaparecidas+2020.pdf/19fca169-a401-432e-928c-a88d23708d04

Spanish Ministry of Interior. (2021). Informe de Personas Desaparecidas -España [Missing Persons Report- Spain]. Retrieved from: https://cndes-web.ses.mir.es/publico/Desaparecidos/dam/jcr:aa217 9e8-dc6a-419a-bbea-0a7134ef5ba2/INFORME\%20ESTADISTICO\%202021\%20ACCESIBLE\% 20(21MB).pdf

Stevenson, E., \& Thomas, S. (2018). A 10 year follow-up study of young people reported missing to the police for the first time in 2005. Journal of Youth Studies, 21(6), 115. https://doi.org/10.1080/13676 261.2018.1468874

Stewart, E. (2018).Missingness: The Social Realities of Physical Absence. Illness, Crisis \& Loss, 1-9https:// doi.org/10.1177/2F1054137318755386

Tarling, R., \& Burrows, J. (2004). The nature and outcome of going missing: the challenge of developing effective risk assessment procedures. International Journal of Police Science \& Management, 6(1), 16-26. https://doi.org/10.1350/ijps.6.1.16.34459

Taylor, C., Woolnough, P., \& Dickens, G. (2018). Adult missing persons: a concept analysis, Psychology, Crime \& Law, 1-24. https://doi.org/10.1080/1068316X.2018.1529230

The National Centre for Missing Persons and Unidentified Remains -NCMPUR-.(2019). 'Missing persons' Fast Fact Sheet". Retrieved from: https://www.canadasmissing.ca/pubs/2019/index-eng.htm

The National Missing Persons Coordination Centre -NMPCC-. (2019). "Missing Persons." Retrieved from: https://missingpersons.gov.au/view-all-profiles.

Thompson, S., Bender, K., \& J. Kim, J. (2011). Family Factors as Predictors of Depression among Runaway Youth: Do Males and Females Differ?. Child and Adolescent Social Work Journal 28, 35-48. https:// doi.org/10.1007/s10560-010-0218-5

Todorović, L. M., \& Butorac, K. (2017). Evidence-Based Approach to Missing Persons Investigation. Journal of Forensic Sciences and Criminal Investigation, 5(5), 14., 5(5), 1. https://doi.org/10.19080/JFSCI. 2017.05.555673.

Tyler, K. A., \& Cauce, A. (2002). Perpetrators of Early Physical and Sexual Abuse among Homeless and Runaway Adolescents. Child Abuse and Neglect, 26, 1261-1274. https://doi.org/10.1016/S01452134(02)00413-1

Woolnough, P., Magar, E., \& Gibb, G. (2019). Distinguishing suicides of people reported missing from those not reported missing: retrospective: Scottish cohort study. British Journal of Psychiatry (Open). https://doi.org/10.1192/bjo.2018.82

Woolnough, P., \& Cunningham, S. (2020). Developmental perspectives on the behaviour of missing children. Psychology, Crime and Law. https://doi.org/10.1080/1068316X.2020.1837130

Publisher's Note Springer Nature remains neutral with regard to jurisdictional claims in published maps and institutional affiliations. 